М. Ю. Горюнова. Реализация эффективных инструментов профессиональной ориентации школьников

Научная статья

УДК 331.548

DOI: 10.18101/2307-3330-2021-1-77-85

\title{
РЕАЛИЗАЦИЯ ЭФФЕКТИВНЫХ ИНСТРУМЕНТОВ ПРОФЕССИОНАЛЬНОЙ ОРИЕНТАЦИИ ШКОЛЬНИКОВ
}

\author{
(C) Горюнова Марина Юрьевна \\ руководитель Центра опережающей профессиональной подготовки \\ Республики Бурятия \\ Россия, 670034, г. Улан-Удэ, ул. Гагарина, 28а \\ copp03@mail.ru
}

\begin{abstract}
Аннотация. В статье рассматриваются проблемы организации профориентационной работы. Представлены анализ предпочтений и жизненных ориентиров будущих выпускников общеобразовательных организаций 2021 г. и результаты участия школьников в проекте «Билет в будущее» за 2019 г. и 2020 г. Обозначены подходы к повышению эффективности процесса профессиональной ориентации школьников через Центр опережающей профессиональной подготовки Республики Бурятия — координатор профориентационной работы в регионе. Показана актуальность профессии профориентолога для всех категорий граждан. Исследовательский вопрос данной статьи заключается в поиске эффективных инструментов профориентации школьников.

Ключевые слова: профессиональная ориентация, механизмы организации профориентации, центр опережающей профессиональной подготовки, профессиональные пробы
\end{abstract}

\section{Для цитирования}

Горюнова М. Ю. Реализация эффективных инструментов профессиональной ориентации школьников // Вестник Бурятского государственного университета. Образование. Личность. Общество. 2021. Вып. 1. С. 77-85.

Введение. Выбор профессии является одним из важнейших и труднейших выборов, совершаемых человеком в жизни. Этот тот выбор определяет направление будущей деятельности человека и во многом его судьбу. Профессиональное самоопределение является частью самоопределения человека, то есть вхождения в ту или иную социальную и профессиональную группу, выбора образа жизни, профессии. Современное понимание профессионального самоопределения охватывает проблемы его взаимосвязи с общим жизненным самоопределением личности, влияния воздействий на личность окружающей социальной среды, профессионального становления и активной жизненной позиции человека. В условиях рыночной экономики особое значение приобретают проблемы свободы выбора профессии и обеспечение конкурентоспособности работника на рынке труда [1]. В связи с этим организация профессионального самоопределения школьников выступает одним из действенных механизмов осознанного выбора профессии. 
В законе РФ №273-Ф3 «Об образовании в РФ» (ст. 2, п. 11; ст. 42, п. 2.4) профессиональная ориентация школьников рассматривается как неотъемлемая часть общего образования. В педагогической науке исследование проблемы организации профориентационной работы идет в разных направлениях. Так, научные основы профориентации исследованы Н. С. Пряжниковым [4], психологопедагогическим проблемам профессиональной ориентации школьников посвящены работы Е. А. Климова [3]; исследования факторов и мотивов, влияющих на выбор профессиональной деятельности, процессы формирования профессиональной направленности в школьном возрасте, отражены в работах Э. Ф. Зеера [42].

Вместе с тем в настоящее время процесс профессиональной ориентации школьников не обеспечивает достижения ожидаемых результатов. Причинами сложившегося положения выступают декларированность и практическое отсутствие государственного статуса профориентации молодежи в России; эпизодичность ее осуществления; неподготовленность учителей и других практических работников к ее реализации; недостаточная связь и преемственность школы, родителей, системы профессионального образования, производства, службы занятости и других социальных институтов, а отсюда - подмена и дублирование функций различными субъектами, ответственными за трудоустройство, обеспечение занятости и в целом за судьбу подрастающего поколения [1].

Проблема профориентации касается не только образования. В промышленном секторе экономики остро стоит вопрос притока молодых, высококвалифицированных профессионалов, например, кадровая служба Улан-Удэнского авиационного завода (УУАЗ) столкнулась в 2020 г. с проблемой дефицита инженернотехнических кадров как со средним профессиональным, так и с высшим образованием. Предприятию требовалось более трех сотен сотрудников, которых завод вынужден был искать за пределами региона.

Кроме того, на уровне приемной кампании в профильные группы авиазавода в образовательных учреждениях региона наблюдался недобор, что очевидно указывает:

1) недостаток выпускников школ, имеющих способности к дисциплинам естественно-научного цикла (физика, математика и т. д.);

2) недостаток информационной работы по освещению возможности получить актуальную, востребованную профессию, качественное образование и достойную работу в регионе.

В таких условиях возрастает значимость системной профориентационной работы, практически персонального сопровождения школьника, консультирования родителей и плотного взаимодействия с работодателями.

Цель и задачи исследования. Исследовательский вопрос: какие направления деятельности по реализации системы профессиональной ориентации наиболее эффективны? Для поиска ответа на поставленный вопрос необходимо выполнить следующие научные задачи:

- проанализировать предпочтения и жизненные ориентиры будущих выпускников общеобразовательных организаций; 
M. Ю. Горюнова. Реализация эффективных инструментов профессиональной ориентации школьников

- $\quad$ определить и реализовать возможности Центра опережающей профессиональной подготовки в обеспечении взаимодействия и координации всех элементов системы профориентации (учащиеся общеобразовательных учреждений, региональные и муниципальные органы власти, родительские сообщества, профориентологи и др.).

Методы исследования: сравнительно-сопоставительный анализ текущего состояния рынка труда; изучение нормативно- правовой документации по проблеме; изучение и обобщение педагогического опыта; наблюдение, анкетирование, статистические методы обработки материалов исследования; изучение и обобщение опыта.

Описание эксперимента. С целью выявления предпочтений и жизненных ориентиров школьников нами проанализированы результаты опроса родителей детей, оканчивающих школу в 2021 г., проведенного сервисом по поиску высокооплачиваемой работы «SuperJob» ${ }^{1}$. Анализ показал, что на выбор продолжения обучения и уровня образования влияет информированность выпускников и родителей о востребованных профессиях и специальностях. По мнению $26 \%$ опрошенных родителей, в 2020 г. приоритетными явились специальности, связанные с информационными технологиями. Поступать в медицинский вуз и стать врачом хотят дети $16 \%$ опрошенных, выучиться на инженера - $11 \%$, экономиста $7 \%$, учителя, военного и менеджера - по $5 \% .4 \%$ родителей выпускников, нацеленных на получение высшего образования, сообщили, что их дети будут учиться на юриста и дизайнера, по 2\% - на филолога или журналиста. Судя по ответам родителей выпускников, которые после школы пойдут в колледжи, самым популярным направлением для поступления является программирование (15\%). Среди наиболее востребованных позиций - юрист и дизайнер (по 12\%), медсестра, музыкант и автомеханик (по 9\%), учитель, строитель и архитектор (по $3 \%)^{2}$.

Будущая профессия влечет за собой выбор учебного заведения. Несмотря на то, что в Республике Бурятия расположено 5 федеральных вузов, 26 республиканских учреждений среднего профессионального образования, в течение двух последних десятилетий наблюдается отток выпускников в регионы с прочной научной базой.

Уже в возрасте 14 лет отличившиеся дети уезжают в математические школыинтернаты для последующего успешного поступления в лучшие вузы страны и после завершения обучения обратно в регион не возвращаются. Ежегодно в Физико-математической школе им. М. А. Лаврентьева при НГУ (г. Новосибирск) обучается около тридцати детей из Бурятии. Причем Бурятия считается одним из регионов, откуда приезжает в эту школу наибольшее количество детей. Соответ-

\footnotetext{
${ }^{1}$ Данные исследовательского центра портала Superjob. URL: https://www. superjob.ru/research/articles/112739/16 (дата обращения: 20.03.2021). Текст: электронный.

${ }^{2}$ Бурятстат. Миграция населения Республики Бурятия. URL: http://burstat.gks.ru/ statcurrentevents/document/105448 (дата обращения: 20.03.2021). Текст: электронный.
} 
ственно в регионе остается преобладающее большинство выпускников с гуманитарными и творческими способностями.

Таким образом, наиболее востребованными среди выпускников 2021 г. выступают медицинские, инженерные, экономические специальности. Жизненные ориентиры выпускников зависят от уровня информированности, степени профессиональной ориентированности и от возможностей учебных учреждений региона: отсутствие условий для получения профессионального образования по выбранной специальности влечет отток молодежи из региона.

Полученные данные подтвердили наше предположение о необходимости институциализации всех процессов системы. Такой структурой выступает Центр опережающей профессиональной подготовки (далее - ЦОПП), открытый в рамках реализации федерального проекта «Молодые профессионалы». В кооперации с потенциальными работодателями ЦОПП координирует развитие и использование ресурсов для организации профессиональной ориентации и опережающего профессионального образования всех категорий граждан по наиболее востребованным, новым и перспективным профессиям и компетенциям на уровне, соответствующем лучшим мировым стандартам и практикам, в том числе международным стандартам «Ворлдскиллс» [3].

Одной из задач деятельности центра является разработка и реализация системы последовательных, научно обоснованных мероприятий, направленных на обеспечение профессионального самоопределения и выбора индивидуального плана обучения. ЦОПП имеет цифровую платформу, возможности которой позволяют организовать сетевое взаимодействие с партнерами: общеобразовательными и профессиональными образовательными организациями, бизнеспартнерами, сообществами работодателей, общественно-профессиональными сообществами, некоммерческими организациями. Отметим, что активная цифровизация всех жизненных циклов влечет за собой изменение педагогических приемов, методов профессионального и активного внедрения в образовательный процесс технологий, основанных на искусственном интеллекте и больших данных. Такие изменения, несомненно, влекут изменения в модели поведения человека в обществе.

В связи с этим для повышения эффективности профориентационной деятельности необходима помощь креативного специалиста-профориентолога, функции которого заключаются в оказании помощи школьникам по нахождению полной и достоверной информации о будущей профессии, выборе учебного заведения, выпускникам - нахождении первого работодателя, опытным карьеристам - смене сферы деятельности и освоении новой профессии. Профориентолог помогает раскрыть потенциал и таланты каждого, детально разбирается в функциях различных профессий и карьерных возможностей, перспективных технологиях. В качестве профориентологов могут выступить школьные психологи, педагоги дополнительного образования и увлеченные своей работой люди.

Нами разработан механизм организации профессиональной ориентации в ЦОПП, который предусматривает работу по основным направлениям: 
M. Ю. Горюнова. Реализация эффективных инструментов профессиональной ориентации школьников

1. Организация курсов повышения квалификации для школьных психологов, педагогов дополнительного образования по овладению новыми профессиональными компетенциями профориентолога. Курсы прошли 25 педагогов республики.

2. Организация профессиональных проб. Начиная с февраля 2020 года на базе Центра школьники и студенты проходят мастер-классы по цифровым и востребованным компетенциям: цифровой куратор, интернет-маркетинг, видеопроизводство, мобильные приложения, сварщик, электромонтаж, графический дизайн, а также через трансформационные игры осваивают «Мир профессий будущего». Только за 2 месяца 2021 г. более 1000 учащихся провели такие пробы.

3. Организация обучения первой профессии обучающихся общеобразовательных организаций. В качестве первой профессии на базе Центра школьника предложены профессии «Цифровой куратор» и «Фотограф» с присвоением по окончании обучения 3-го разряда.

4. Создание необходимых условий, разработка и внедрение образовательных программ для обеспечения возможности изучения предметных областей «Технология», «Физика», «Информатика». Отметим, что в рамках национального проекта «Образование» до 2024 г. в 300 школах республики будут созданы и оснащены современным оборудованием так называемые «Точки роста» по цифровым, естественно - научным, техническим и гуманитарным профилям обучения. Кроме этого, используется материальная база организаций, имеющих высокооснащенные ученико-места: это стационарный и два мобильных детских технопарков «Кванториум». В феврале 2021 г. были организованы курсы повышения квалификации для 20 учителей технологии общеобразовательных школ по теме «Создание видеоурока: проектирование уроков с использованием цифровых образовательных технологий».

5. Организация профориентационной работы в рамках реализуемых федеральных и региональных проектов. Так, начиная с 2019 г. в республике реализуется федеральный проект «Билет в будущее», направленный на раннюю профессиональную ориентацию школьников 6-11-х классов. В неблагоприятных эпидемиологических условиях 2020 г. в рамках проекта «Билет в будущее» профессиональными пробами было охвачено только 14\% школьников (в 2019 г. - 44\%), а усложнение процедуры регистрации детей на платформу сократило доступ детей к профпробам (рис.). 


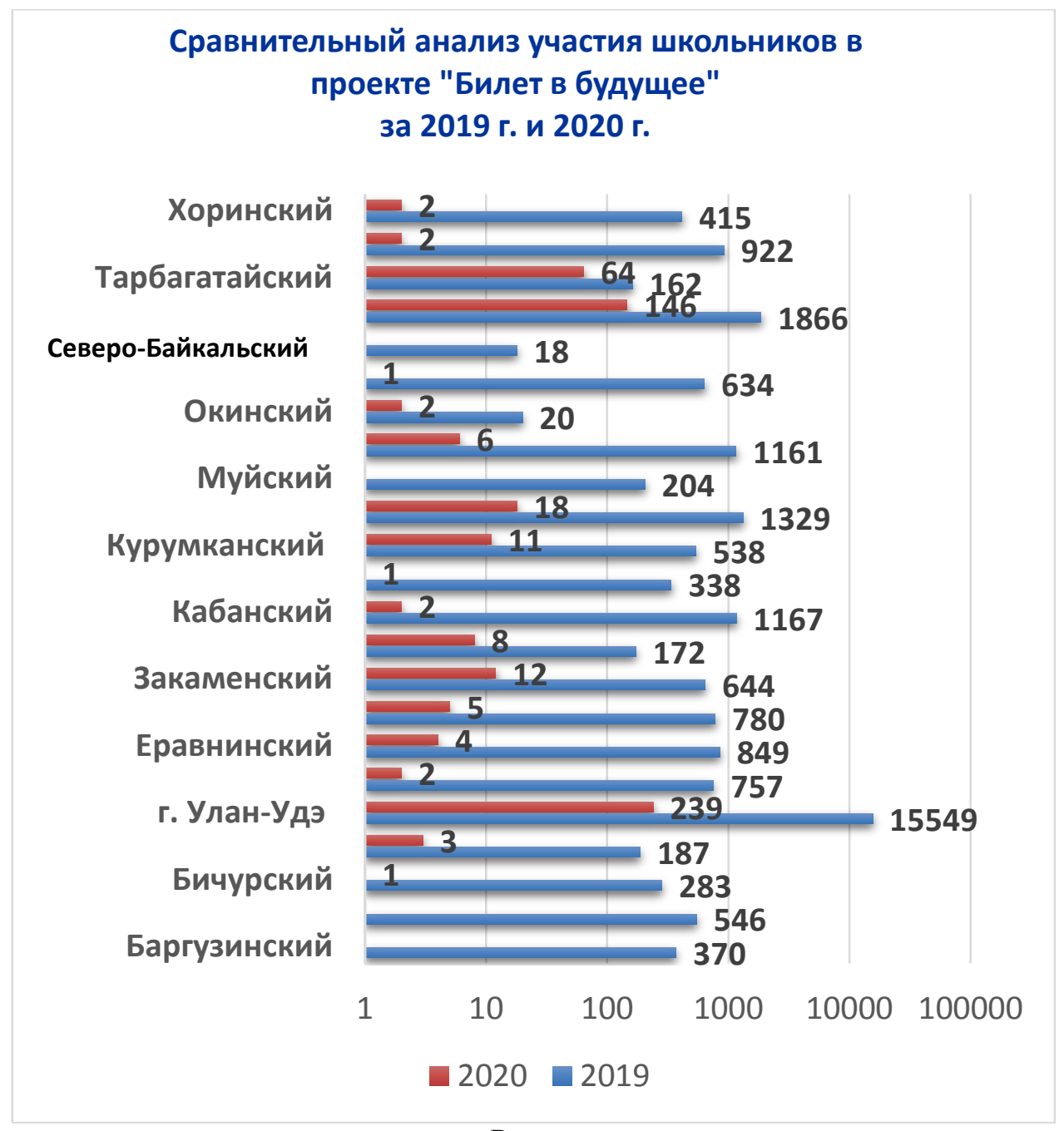

Рис.

\section{Результаты эксперимента}

Сравнительный анализ двухгодичных результатов проекта показал, что функциональность и компетенции Центра опережающей профессиональной подготовки достаточны для организации процессов взаимодействия всех элементов системы образования и проведения массовых профессиональных проб.

Вместе с тем профориентационное пространство Республики Бурятия насыщено множеством ресурсов, значимых для профессионального самоопределения детей и молодежи. Возможности таких ресурсов должны целенаправленно и комплексно использоваться в рамках реализации основных задач профориентационной деятельности:

- программы дополнительного образования детей, имеющие практикоориентированную, предпрофессиональную или профильную направленность; 
М. Ю. Горюнова. Реализация эффективных инструментов профессиональной ориентации школьников

Таблииа 1

Результаты реализации проекта «Билет в будущее» за 2 года в Бурятии

\begin{tabular}{|l|c|c|}
\hline \multicolumn{1}{|c|}{ Показатель } & 2019 & 2020 \\
\hline $\begin{array}{l}\text { Всего детей, с 6-го по 11-й класс в Республике Буря- } \\
\text { тия, чел. }\end{array}$ & 60781,00 & 66232,00 \\
\hline $\begin{array}{l}\text { Количество зарегистрированных на платформе детей в } \\
\text { РБ, чел. }\end{array}$ & 26664,00 & 9085,00 \\
\hline $\begin{array}{l}\text { Количество пройденных тестов школьниками из РБ, } \\
\text { шт. }\end{array}$ & 14532,00 & 21403,00 \\
\hline $\begin{array}{l}\text { Количество площадок, шт. } \\
\text { Количество компетенций, шт. }\end{array}$ & 6,00 & 13,00 \\
\hline Количество активированных школ, шт. & 408,00 & 43,00 \\
\hline Сроки реализации проекта, мес. & 3,00 & 7,00 \\
\hline Количество детей с ОВ3, чел. & 20,00 & 70,00 \\
\hline Количество профессиональных проб, шт. & 1974,00 & 1707,00 \\
\hline $\begin{array}{l}\text { Кол-во детей, прошедших профессиональные пробы, } \\
\text { чел. }\end{array}$ & 7545,00 & 733,00 \\
\hline
\end{tabular}

- профориентационные возможности школьного курса технологии и других образовательных областей общеобразовательной программы (в т. ч. в соответствии со ст. 66.3 Федерального закона от 29.12.2012 № 273-Ф3 «Об образовании в Российской Федерации»);

- профориентационные мероприятия, проводимые в рамках федерального проекта ранней профориентации школьников «Билет в будущее»;

- $\quad$ конкурсы профессионального мастерства, в т. ч. «Молодые профессионалы» (WorldSkills Russia и WorldSkills Russia Juniors), Национальный чемпионат по профессиональному мастерству среди инвалидов и лиц с ограниченными возможностями здоровья «Абилимпикс»;

- традиционные профориентационные мероприятия для школьников, систематически проводимые организациями профессионального образования;

- интернет-ресурсы различного типа, отражающие актуальное состояние экономики, профессионального и высшего образования, рынка труда и профессий.

Таким образом, инвентаризация и упорядочение систематически проводимых в пределах Республики Бурятия профориентационных мероприятий способству- 
ют повышению качества и согласованности в существующей системе профессионального самоопределения. Включение в цифровую платформу ЦОПП работающего раздела «Профориентация» обеспечивает эффективную горизонтальную координацию действий всех институциональных субъектов, участвующих в решении текущих задач функционирования деятельности.

Результатом построения комплексной работы через ЦОПП должно стать формирование у детей и молодежи (в том числе инвалидов и лиц с ОВ3) Республики Бурятия устойчивой способности к самостоятельному, ответственному и осознанному профессионально-образовательному выбору, к непрерывному профессиональному развитию и построению карьеры в условиях динамично развивающегося рынка труда региона, быстро меняющихся технико-технологических основ современного производства.

\section{Литература}

1. Бабушкин Г. Д. Психологические основы формирования профессионального интереса к педагогической деятельности. Омск: ОГИФК, 1990. 186 с. Текст: непосредственный.

2. Зеер Э. Ф. Психология профессий: учебное пособие для студентов педвузов. Москва: Академический Проект; Екатеринбург: Деловая книга, 2003. 113 с. Текст: непосредственный.

3. Климов Е. А. Психология профессионального самоопределения. Ростов-на-Дону: Феникс, 1996. 509 с. Текст: непосредственный.

4. Пряжников Н. С. Профессиональное и личностное самоопределение. Москва; Воронеж, 2011463 с. Текст: непосредственный.

5. Чистякова С. Н. Теоретические подходы к профессиональному самоопределению обучающихся. URL: http://www.мой-ориентир.pф/teoreticheskie-podkhody/ (дата обращения: 20.03.2021). Текст: электронный.

Статья поступила в редакиию 25.01.2021; одобрена после рецензирования 25.02.2021; принята к публикациии 09.04.2021.

\section{IMPLEMENTATION OF EFFECTIVE TOOLS FOR PROFESSIONAL ORIENTATION OF SCHOOLCHILDREN}

Marina Yu. Goryunova

Head of the Center for Advanced Vocational Training of the Republic of Buryatia 28a Gagarina St., Ulan-Ude 670034, Russia

copp03@mail.ru

Abstract. The article deals with the problems of occupational guidance for schoolchildren. We present an analysis of the preferences and life guidelines of future graduates from educational organizations in 2021, and the results of schoolchildren participation in the project "Ticket to the Future" in 2019 and 2020. The article considers the approaches to increase the efficiency of the process of occupational guidance for schoolchildren through the Center for Advanced Professional Training of the Republic of Buryatia, emphasizes the importance of occupational guidance for all categories of citizens, including schoolchildren. 
M. Ю. Горюнова. Реализация эффективных инструментов профессиональной ориентации школьников

Keywords: occupational guidance; mechanisms for organizing occupational guidance; center for advanced professional training; vocational tests.

\section{For citation}

Goryunova M. Yu. Implementation of Effective Tools for Professional Orientation of Schoolchildren. Education. Person. Society. 2021; 1: 77-85 (In Russ.).

The article was submitted 25.01.2021; approved after reviewing 25.02.2021; accepted for publication 09.04.2021. 